Original Research Paper

\title{
Genetic Characterization of Kazakh Native Sheep Breeds Using Mitochondrial DNA
}

\author{
${ }^{1}$ Ilmira Mukhametzharova, ${ }^{1}$ Yessenbay Islamov, \\ ${ }^{1}$ Saukymbek Shauyenov, ${ }^{1}$ Dulat Ibrayev, ${ }^{2}$ Sabina Atavliyeva and ${ }^{2}$ Pavel Tarlykov

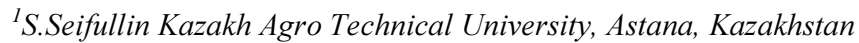 \\ ${ }^{2}$ National Center for Biotechnology, Astana, Kazakhstan
}

Article history

Received: 08-05-2018

Revised: 07-08-2018

Accepted: 6-09-2018

Corresponding Author:

Ilmira Mukhametzharova S.

Seifullin Kazakh Agro

Technical University, Astana,

Kazakhstan

Email:

ilmiramukhamet@gmail.com

\begin{abstract}
In this study, we used mitochondrial (mt) DNA to reveal patterns of genetic diversity among six breeds of sheep native to Kazakhstan, including the Chu and Kalchengel types of Kazakh mutton-semifine-wool breed of sheep, Akzhayik, Edilbay, Kazakh fat-rumped semi-course-wool and South Kazakh Merino breeds. Mitochondrial DNA D-loop was studied in 64 samples to determine the genetic diversity of the local sheep breeds. The analysis identified 54 haplotypes and 113 polymorphic loci of mtDNA D-loop. For the studied breeds, haplotype diversity and nucleotide diversity were $0.993 \pm 0.005$ and $0.039 \pm 0.001$, respectively. The results indicated higher level of nucleotide diversity in the South Kazakh Merino (SKM) breed (0.047), while the lowest diversity was observed in the Edilbay breed (0.029). In addition, the average number of nucleotide differences (Kxy) and the average number of nucleotide substitutions (Dxy) were determined among the studied breeds. The minimal value of genetic distance was observed between Akzhayik mutton-wool and Kazakh fat-rumped semicourse-wool breeds (Kxy: 16.956 and Dxy: 0.039), while the maximum value was observed between the Edilbay and SKM breeds (Kxy: 24.600 and Dxy: 0.040). Phylogenetic analysis revealed the presence of three haplogroups, namely, $\mathrm{A}, \mathrm{B}$ and $\mathrm{C}$ in the collected sample, while the haplogroups $\mathrm{D}$ and $\mathrm{E}$ were not found. The results indicated that 28 of 64 tested animals belong to haplogroup A $(43.75 \%)$, whereas 25 of investigated animals were attributed to haplogroup B (39.06\%) and 11 animals to haplogroup C (17.19\%).
\end{abstract}

Keywords: Kazakh Native Sheep Breeds, MtDNA, Diversity, Haplotypes, Phylogeny

\section{Introduction}

The most feasible area of sheep domestication is Iran, southern Central Asia, the southwestern Asia and other eastern regions; also North Africa and the Sahara, where mouflons were still in the Stone Age, are not excluded. Excavations in the regions of Egypt, Mesopotamia, in the valleys of other subtropical rivers, on the shores and islands of the Mediterranean, have shown that animal husbandry; in particular sheep breeding has changed and climbed to the highest level. This was facilitated by the success of agriculture in the valleys of the rivers of slave states, where they harvested two or even three crops a year (Torekhanov et al., 2011; Abilov et al., 2012; Lushnikov et al., 2013; Rasali et al., 2006).
Sheep breeding in Kazakhstan is a traditional, historically developed animal husbandry sector, the development of which is favored by the presence of extensive natural pastures (Ombayev et al., 2013; Berus et al., 2013). Currently, fine-fleeced, semi-finefleeced, coarse-wool and semi-course-wool directions represent sheep breeding of the republic.

In Kazakhstan, mutton-semifine-wool sheep breeding started to develop more intensively since the beginning of the 1960, when the Republic purchased a large batch of sheep of English long semi-fine-wool breeds. So from England in September of 1962 a group of semifine-wool sheep Lincoln and Romney-march in the amount of 131 heads (26 rams and 105 dams) was brought to the Alma-Ata region, 187 rams and 127 
female lambs of Lincoln and Romney-march arrived to the North Kazakhstan from Argentina at the end of 1961, from Russia 63 rams of Romney-march were delivered. Soon work with imported animals was carried out practically on all territory of Kazakhstan (Balmont, 1965). Currently, scientific research is being carried out to improve and create new and existing genotypes of mutton-semifine-wool sheep breeds (Shauyenov et al., 2016; Traisov et al., 2015). Preservation of breed diversity of domesticated species is important for ensuring sustainable development of agriculture, addressing global food security problems. To preserve the breed and level out the adverse consequences of the downsizing, it is necessary to use modern approaches for assessing and maintaining intrabreed genetic diversity.

One of the most accessible and effective DNA markers for population-genetic studies is the hypervariable region of the mitochondrial DNA control region, which allows tracing the lines of the maternal animal gene pool, due to the lack of recombination and inheritance on the maternal line. This, in turn, provides an opportunity to determine genetic diversity, structure, phylogenetic relationships, etc.

Mitochondrial DNA (mtDNA) is located outside the nucleus of eukaryotic cells and has both coding and noncoding regions, ranging in length from 15 to $20 \mathrm{~kb}$ in different species. The non-coding region is called the control region, which includes the D-loop. The rate of mtDNA evolution occurs about 5-10 times more rapidly than that of nuclear DNA (Upholt and Dawid, 1977). Since mtDNA is inherited solely from the maternal line and commonly shows haplotype diversity within species, it is an important material for phylogenetic inference and analysis of genetic diversity at or below the species level (Wolf et al., 1999).

Mitochondrial sequencing was used to explain the origin of many modern species of domestic animals, including sheep, goats, pigs, yaks, taurine and indicine cattle and others. Previous studies on goats (Fernandez et al., 2006; Luikart et al., 2001), cattle (Bradley et al., 1996; Loftus et al., 1994) and pigs (Larson et al., 2005) have revealed various maternal clades or lineages. The presence of numerous mtDNA lines and their mixing within breeds (Chen et al., 2006; Meadows et al., 2007; 2005; Pedrosa et al., 2005; Pereira et al., 2006) can be caused by several events of domestication and subsequent selection or introgression between domestic and wild species.

Using control region of mtDNA, five phylogenetically divergent maternal lineages of domestic sheep (Ovis aries), also known as haplogroups A, B, C, $\mathrm{D}$ and $\mathrm{E}$ have been reported (Meadows et al., 2007; Pedrosa et al., 2005; Hiendleder et al., 2002; Tapio et al., 2006). The major haplogroups $A$ and $B$ are both common in Asia, while B dominates in Europe. Haplogroup C was found in Portugal, Turkey, the Caucasus and China. Haplogroup D, present in Romanian Karachai and Caucasian animals, may be associated with haplogroup A. Haplogroup E was found in the Middle East, Syria, Israel and Turkey (Tapio et al., 2006).

In this study, we used mtDNA to reveal patterns of genetic diversity among six breeds of sheep native to Kazakhstan, which have different phenotypic characteristics. Mitochondrial DNA D-loop was studied in 64 samples to determine the genetic diversity of sheep breeds. The genetic diversity of the studied breeds was estimated on the basis of haplotype diversity and nucleotide diversity. Phylogenetic analysis of the sheep breeds was carried out and information on their genetic origin was obtained.

The aim of the study is to research the genetic diversity and the phylogeny of sheep populations in Kazakhstan using mitochondrial DNA as a genetic marker for studying the migration and origins of the modern sheep.

Investigation of mitochondrial DNA is widely used for studying domestication, migration and origin of the domestic sheep. Noteworthy, analysis of the mitochondrial DNA of wild and modern sheep has facilitated the study of the origin of the domestic sheep, indicating that the mouflon (Ovis orientalis) is the ancestor of a domesticated sheep. To date, five phylogenetically divergent lineages of mitochondrial DNA have been identified in domestic sheep.

Genetic data on local sheep populations is especially relevant for the Central Asian region, in the light of the centuries-old nomadic way of life of people living here. It should be noted that at present very few genetic studies of domestic sheep have been carried out in Kazakhstan, therefore studies on population genetics of local sheep breeds are in huge demand.

The information obtained as a result of the analysis of the nucleotide sequence of the D-loop of mitochondrial DNA made it possible to establish the genealogical structure of the sheep breeds studied in a direct maternal line, to evaluate the genetic differentiation of the sheep subpopulations and to reveal the phylogenetic relationships between the breeds.

The data obtained on the genetic and genealogical structure of sheep can provide valuable data for further monitoring of the domestic sheep breeds and the preservation of the genetic diversity of the population.

\section{Materials and Methods}

\section{Sample Collection and DNA Extraction}

Sixty-four blood samples of sheep, representing six breeds were obtained from local farms using vacuum tubes with an anticoagulant EDTA (Terumo). The 
samples belonged to sheep breeds of different types including Chu type of Kazakh mutton-semifine-wool sheep (CSF, 10 samples), Kalchengel type of Kazakh mutton-semifine-wool sheep (KSF, 17 sequences), Akzhayik Mutton-Wool sheep (AMW, 9 sequences), Edilbay sheep (EDB, 8 sequences), Kazakh fat-rumped semi-course-wool sheep (KFR, 10 sequences) and South Kazakh Merino sheep (SKM, 10 sequences).

Extraction and purification of DNA from blood were completed using Wizard ${ }^{\circledR}$ Genomic DNA Purification Kit (Promega) according to the protocol of the manufacturer.

\section{Amplification and mtDNA Sequencing}

Sequencing of the mitochondrial DNA control region was carried out using the primers shown in Table 1. The sequence length of control region is 539 base pairs and corresponds to the 15389-16556 positions of the reference sequence (gi: 3445513 ). The PCR amplification was conducted in a reaction mixture containing dNTP mix (10 mM ea), 10x Taq Buffer with $\mathrm{KCl}, 2.5 \mathrm{mM} \mathrm{MgCl}_{2}, 1$ unit of Taq polymerase and 10 pmol of each primer in a volume of $0.5 \mu \mathrm{L}$. The reaction was permormed in a $\mathrm{T}-100$ Thermal Cycler (BioRad) using the following amplification protocol: $95^{\circ} \mathrm{C}$ for $5 \mathrm{~min}, 30$ cycles: $95^{\circ} \mathrm{C}$ for $30 \mathrm{sec}, 61^{\circ} \mathrm{C}$ for $40 \mathrm{sec}, 72^{\circ} \mathrm{C}$ for $60 \mathrm{sec}$, $72^{\circ} \mathrm{C}$ for $5 \mathrm{~min}$ and storage at $4^{\circ} \mathrm{C}$. Dephosphorylation of dNTPs and purification of PCR products from the remaining primers in the post-PCR mixture was carried out by incubation of alkaline phosphatase and exonuclease I enzymes at $37^{\circ} \mathrm{C}$ for $30 \mathrm{~min}$, followed by inactivation at $85^{\circ} \mathrm{C}$ for $10 \mathrm{~min}$.
The nucleotide sequence was determined using the BigDye ${ }^{\circledR}$ Terminator v3.1 Cycle Sequencing Kit and the 3730 Genetic Analyzer (Applied Biosystems) according to manufacturer's instructions. The same set of primers was used sequence-PCR reaction (3.2 $\mathrm{ng} / \mu \mathrm{l})$. The alignment and comparative analysis of the obtained sequences were carried out using the reference sequence of Ovis aries complete mitochondrial genome (gi: 3445513) using SeqScape 2.6 program (Applied Biosystems).

The mitochondrial DNA haplogroups were determined based on five nucleotide positions of the mtDNA control region $(15459,15476,15484,15509$ and $15512)$ with respect to the reference sequence (AF010406). CFX96 Real-Time PCR Detection System (BioRad) was used to amplify sheep DNA in a reaction mixture containing sequence-specific primers and TaqMan probes according to manufacturer's instructions (Life Technologies) (Table 2). Accumulation of fluorescence was analyzed for the VIC and FAM channels. The analysis was carried out using the software CFX Manager 3.1 (BioRad).

\section{Data Analysis}

To align the mtDNA D-loop sequences BioEdit software was used the (Hall, 1999). Structure of haplotypes, haplotype and nucleotide diversity, the average number of nucleotide differences (Kxy) and the average number of nucleotide substitutions (Dxy) between breeds were calculated using the DnaSP 6.00 software.

Neighboring-Joining tree ( $\mathrm{NJ}$ ) was constructed using the Mega version 6.0 software.

Table 1: Primers for amplification of the mitochondrial DNA control region

\begin{tabular}{lc}
\hline Sequence & Name \\
\hline F 5\#-CCCCACTATCAACACCCAAA-3\# & OarCR15389-15410 \\
R 5\#-CATGGTGAACAAGCTCGTGA-3\# & OarCR29-48H \\
F 5\#-TGCTTGACCGTACATAGTACAT-3\# & \\
R 5\#-CATCTAGGCATTTTCAGTGCC-3\# & \\
\hline
\end{tabular}

Table 2: Primers and probes for determining the mitochondrial DNA haplogroup

\begin{tabular}{|c|c|c|}
\hline $\begin{array}{l}\text { mtDNA position } \\
\text { (AF010406) }\end{array}$ & Sequence of primers, 5 ' to 3 ' & Sequence of probes, 5 ' to 3 ' \\
\hline \multirow[t]{2}{*}{15459} & F-ACACCCAAAGCTGAAGTTCTACTTAAA & VIC-CAACGATACTTATCAATATAT \\
\hline & R- TTTTAGCAAGTTTAATACTGGAGAGGTTCTT & FAM-TCAACGATACTTATTAATATAT \\
\hline \multirow[t]{2}{*}{15476} & F-CTTAAACTATTCCCTGAATCATTATCAACGATACT & VIC-AGGCTCTTTATATTTTTG \\
\hline & R-TCCGTGTTGTATGTTTGGGAGTTTT & FAM-AGGCTCTTTATGTTTTTG \\
\hline \multirow[t]{2}{*}{15484} & F-CTATTCCСТGAATCATTATCAACGATACTTATCA & VIC-ACTGGAGAGGCTCTTTA \\
\hline & R-TCCGTGTTGTATGTTTGGGAGTTTT & FAM-ACTGGAGAGGTTCTTTA \\
\hline \multirow[t]{2}{*}{15509} & F-CCAAAAATATAAAGAGCCTCTCCAGTATTAAACT & VIC-ATGTTTGGGAGTTTTAGCA \\
\hline & R-GAGTGGGAAGTCCGTGTTGT & FAM-ATGTTTGGGAGTCTTAGCA \\
\hline \multirow[t]{2}{*}{15512} & F-AATATATTTCCAAAAATATAAAGAGCCTCTCCAGT & VIC-AAACTTGCTAAAACTTCCCAC \\
\hline & R-GGGTTGTTATGTGGGCTTGTG & FAM-AACTTGCTAAAACCTCCCAC \\
\hline
\end{tabular}




\section{Results}

Mitochondrial DNA was used to study genetic diversity among six breeds of sheep native to Kazakhstan, including the Chu and Kalchengel types of Kazakh mutton-semifine-wool breed of sheep, Akzhayik, Edilbay, Kazakh fat-rumped semi-course-wool and South Kazakh Merino breeds.

About 64 samples belonging to 6 sheep breeds were analyzed to determine the natural genetic diversity using a sequence of the control region of 539 base pairs of the D-loop mtDNA. Analysis of this region revealed 113 polymorphic sites, which led to the formation of 54 haplotypes in 64 studied animals (Table 3).

Studies of many scientists on sheep from the Egyptian and Italian sheep breeds (Othman et al., 2015), Iranian sheep (Rafia and Tarang, 2016), Polish sheep (Koseniuk and Slota, 2016), Nepalese sheep (Gorkhali et al., 2015) were presented. The fragment of the D-loop region used in these studies varied from 76 to 721 b.p., with 55-132 polymorphic sites.

Within all tested breeds, the haplotype diversity $(\mathrm{Hd})$ and the average number of pairwise differences $(\mathrm{K})$ were 0.993 and 21.029, respectively.

Among the six investigated sheep breeds, the total nucleotide diversity was $0.039 \pm 0.001$.

An average number of nucleotide differences (Kxy) and the average number of nucleotide substitutions (Dxy) were determined between the breeds. The lowest genetic distance was observed between AMW and KFR (Kxy: 16.956 and Dxy: 0.039), followed by the distance between CSF and EDB (Kxy: 19.225 and Dxy: 0.036) and the distance between CSF and AMW (Kxy: 19.300 and Dxy: 0.036). The highest genetic distance was observed between EDB and SKM (Kxy: 24.600 and Dxy: 0.040), followed by the distance between KFR and SKM (Kxy: 22.980 and Dxy: 0.042 ), whereas the distance between KSF and SKM was 22.700 for Kxy and 0.043 for Dxy (Table 4).

Table 3: The genetic diversity data of the six tested sheep breeds

\begin{tabular}{lllllll}
\hline Breed & ID & N & Hn & $\pi$ & Hd & S \\
\hline Kazakh mutton-semifine-wool sheep, Chu type & CSF & 10 & 10 & 0.039 & 1.000 & 61 \\
Kazakh mutton-semifine-wool sheep, Kalchengel type & KSF & 17 & 14 & 0.045 & 0.978 & 77 \\
Akzhayik mutton-wool & AMW & 9 & 9 & 0.031 & 1.000 & 46 \\
Edilbay & EDB & 8 & 5 & 0.029 & 0.786 & 44 \\
Kazakh fat-rumped semi-course-wool & KFR & 10 & 9 & 0.034 & 0.978 & 51 \\
South Kazakh Merino & SKM & 10 & 10 & 0.047 & 1.000 & 75 \\
Total & & 64 & 54 & 0.039 & 0.993 & 113
\end{tabular}

a. ID: Identity Document; N: Number of sequences; Hn: number of observed haplotypes; $\pi$ : population nucleotide diversity; Hd: Haplotype diversity, S: number of polymorphic sites

Table 4: Average pairwise differences between populations

\begin{tabular}{lllllll}
\hline & CSF & KSF & AMW & EDB & KFR & SKM \\
\hline CSF & - & 0.036 & 0.036 & 0.036 & 0.041 & 0.046 \\
KSF & 20.947 & - & -037 & 0.031 & 0.039 & 0.043 \\
AMW & 19.300 & 20.725 & 19.486 & - & 0.039 & 0.041 \\
EDB & 19.225 & 22.184 & 16.956 & 19.350 & 0.038 & 0.040 \\
KFR & 19.950 & 21.247 & 21.833 & 24.600 & - & 0.042 \\
SKM & 21.950 & 22.700 & 22.980 & - \\
\hline
\end{tabular}

a. Average number of nucleotide difference between populations, Kxy (below); b. Average number of nucleotide substitution per site between populations, Dxy (above)

Table 5: Locations, sample sizes and haplogroup frequencies of the breeds

Haplogroup frequencies, $\%(n)$

\begin{tabular}{lllllllll} 
Breed name & Location & Latitude & Longitude & Sample size & A & B & C & D, E \\
\hline CSF & South-East KZ & 43.6285 & 73.8674 & 10 & $50(5)$ & $30(3)$ & $20(2)$ & - \\
KSF & South-East KZ & 43.6285 & 73.8674 & 17 & $41(7)$ & $29(5)$ & $29(5)$ & - \\
AMW & West KZ & 50.9070 & 50.4596 & 9 & $33(3)$ & $67(6)$ & - & - \\
EDB & West KZ & 49.6452 & 51.806 & 8 & $75(6)$ & $25(2)$ & - & - \\
KFR & Central KZ & 49.9091 & 71.5712 & 10 & $40(4)$ & $60(6)$ & - & - \\
SKM & South-East KZ & 43.6285 & 73.8674 & 10 & $30(3)$ & $30(3)$ & $40(4)$ & - \\
Total & & & & 64 & $43,75(28)$ & $39,06(25)$ & $17,19(11)$ & - \\
\hline
\end{tabular}




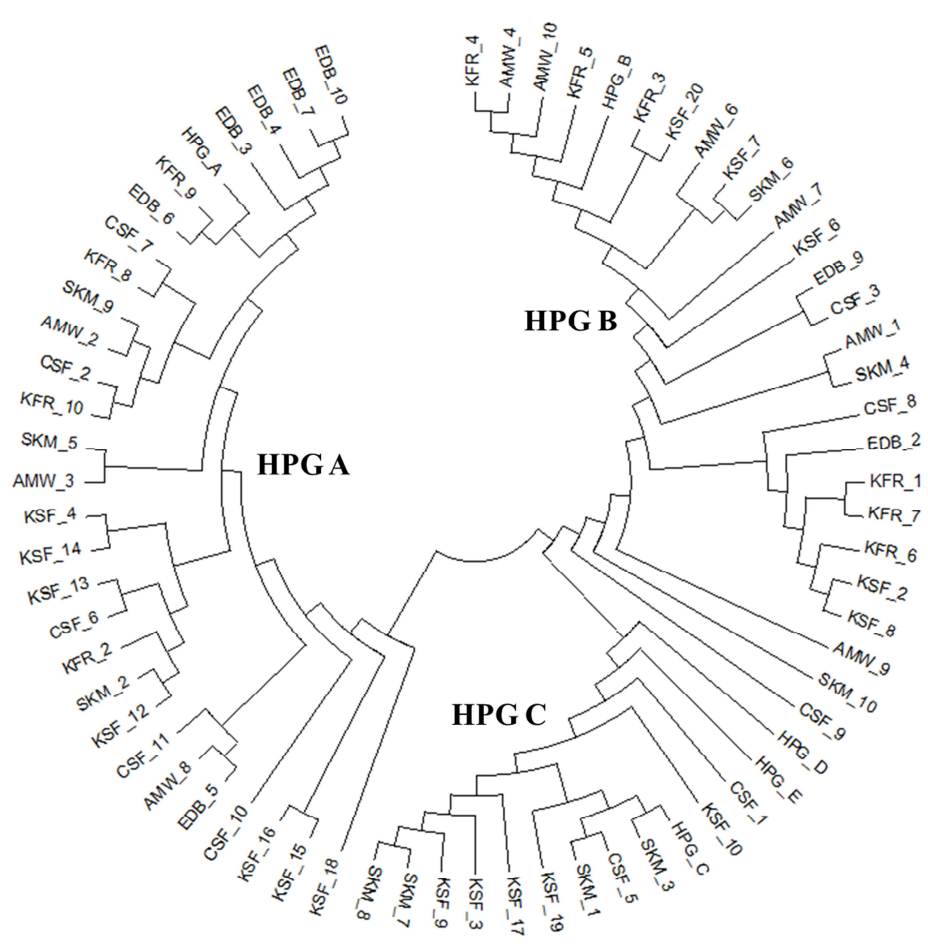

Fig. 1: The Neighbor-Joining tree of mtDNA coding region sequences of the collected sheep sample as a circle

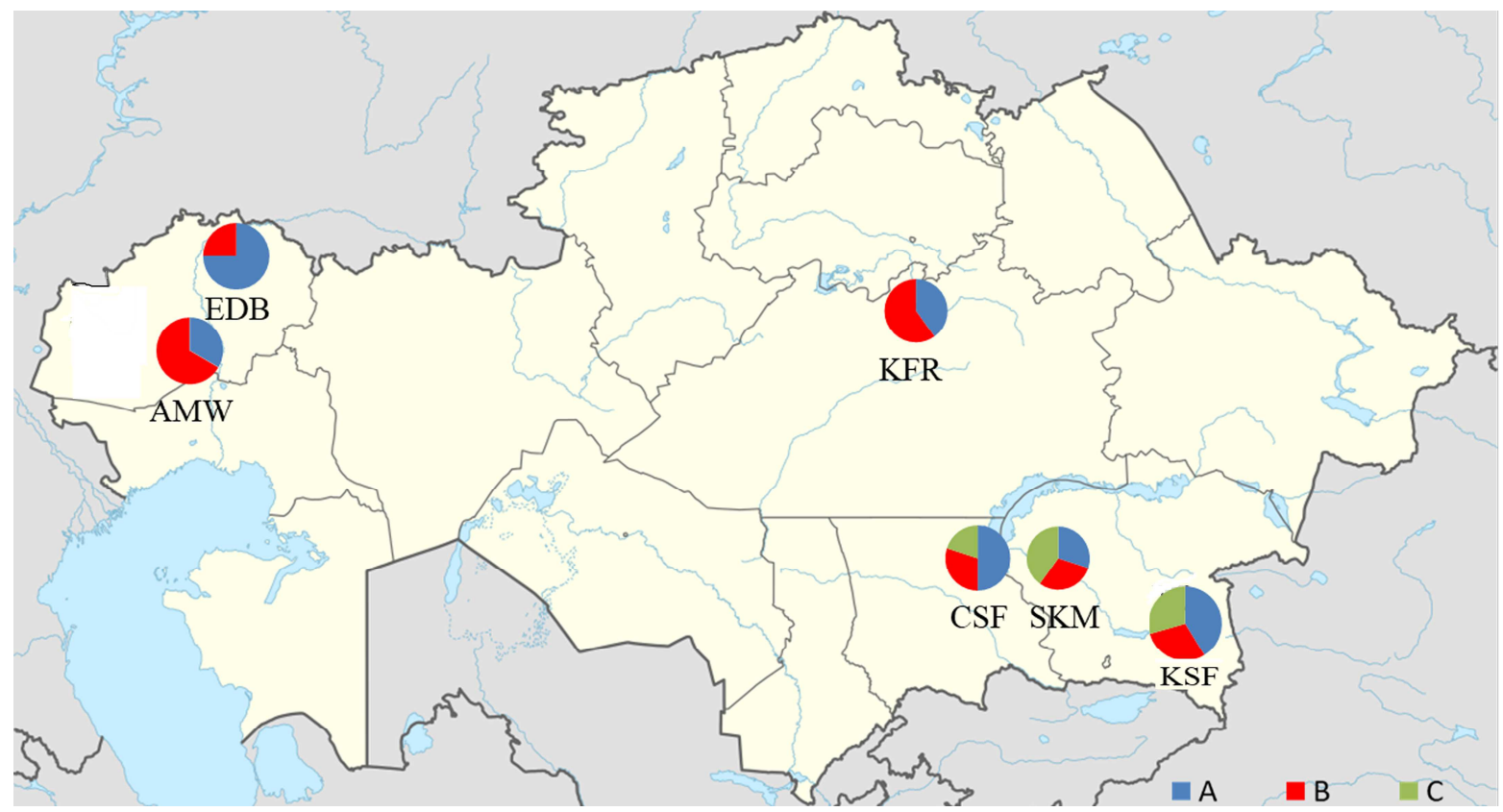

Fig. 2: The sampling sites and haplogroup composition of the sheep breeds on the map of Kazakhstan

The tree with the sum of branch length $=0.37$ is shown. The evolutionary distances were computed using the Maximum Composite Likelihood method and are in the units of the number of base substitutions per site.

The neighboring-joining tree (Fig. 1) demonstrated the presence of three (A, B, C) of five haplogroups. The other two haplogroups described in the literature (D and E) were not found in the collected sample. The results of the study (Table 5) showed that 28 of 64 tested animals were assigned to haplogroup A (43.75\%), while 25 test animals are grouped in haplogroup B (39.06\%) and 11 animals in haplogroup C (17.19\%). 
About 28 (43.75\%) of 64 studied sheep were classified as haplogroup A, in the CSF (50\%), KSF (41\%) and Edilbay $(75 \%)$ breeds this haplogroup is dominant. Haplogroup $\mathrm{C}$ is less common, it is found in the CSF (20\%), KSF (29\%) and SKM (40\%) sheep breeds.

The pie charts (Fig. 2) indicate geo locations of the collection sites of the native sheep breeds. Table 3 for the abbreviations.

\section{Discussion}

Mitochondrial DNA has been widely used by scientists to analyze the phylogenetic relationships between or within species in livestock (Watanabe et al., 1989; Tanaka et al., 1996; Sasazaki et al., 2006).

Statistical analysis of genetic diversity within 6 sheep breeds indicated that the highest number of haplotypes (14 haplotypes, 17 samples) was found in Kalchengel type of Kazakh mutton-semifine-wool sheep breed with a total of 77 polymorphic sites, while the lowest number of haplotypes were found in the Edilbay sheep breed with 44 polymorphic sites (5 haplotypes, 8 samples). Chu type of Kazakh mutton-semifine-wool sheep breed had 61 polymorphic sites (10 haplotypes 10 samples), Akzhayik mutton-wool sheep breed (9 samples) had 46 polymorphic sites forming 9 haplotypes. In the Kazakh fat-rumped semicourse-wool (10 samples) and South Kazakh merino (10 samples) sheep breeds were found 51 and 75 polymorphic sites, forming 9 and 10 haplotypes, respectively.

The maximum haplotype diversity among the 6 studied breeds was 1.00 in the Chu type of Kazakh mutton-semifine-wool sheep breed, Akzhayik and South Kazakh merino sheep breeds (where the average number of pairwise differences $\mathrm{K}=23.911,19.000$ and 28.044, respectively). Due to the small number of studied Edilbay sheep breed animals, the haplotype diversity was 0.786 , where $\mathrm{K}=17.143$. In turn, in the Kalchengel type of Kazakh mutton-semifine-wool and Kazakh fat-rumped semi-coursewool sheep breeds, the haplotype diversity in both was 0.978 . The results showed that highest nucleotide diversity among the six tested breeds was in the South Kazakh merino breed (0.047) and the lowest in Edilbay, where it was 0.029. In turn, the nucleotide diversity in the Akzhayik, Kazakh fatrumped semi-course-wool, CSF and KSF sheep breeds was $0.031 ; 0.034 ; 0.039$ and 0.045 , respectively.

The values of haplotype and nucleotide diversities observed in this study was higher than haplotype diversity of $0.992 \pm 0.010$ and nucleotide diversity of $0.019 \pm 0.001$, respectively obtained from analysis of mtDNA variation and matrilineal structure in Tibetan sheep populations of Qinghai-Tibetan Plateau, China (Liu et al., 2016).

The analysis involved 69 nucleotide sequences, including 5 reference sequences representing haplogroups $\mathrm{A}, \mathrm{B}, \mathrm{C}, \mathrm{D}$ and E. All positions containing gaps and missing data were eliminated.
The analysis of mtDNA sequences was not suitable for establishing detailed relationships between the studied breeds. Phylogenetic analysis indicated that differences within each major branch were less pronounced than expected. The phylogenetic tree did not show any definite genetic structure among the studied breeds, what may be explained by a strong flow of genes and their mixing among sheep populations, probably caused by the extensive transportation and trade of sheep in history (Meadows et al., 2005; Pedrosa et al., 2005).

Haplogroups A and B are the most frequent and have been found in all studied sheep breeds. Haplogroup A is particularly prevalent in Asia and it indicates that Kazakh mutton-semifine-wool and Edilbay sheep are genetically closer to Asiatic sheep breeds than the Akzhayik muttonwool breed, where haplogroup B was dominant (67\%), occurring with a high frequency in breeds selected in Europe and in countries of the Eastern Mediterranean. In the South Kazakh merino sheep breed, haplogroups A, B and C are present in almost equal proportions.

Haplogroup C was dominant in the South Kazakh merino sheep breed, what consistent with the literature in which it is reported the presence of haplogroup $\mathrm{C}$ in steppe and semi-desert regions and exist mainly in Central Asia, India and China, as well as in the Caucasus and the Iberian cave (Europe) (Meadows et al., 2005; Pedrosa et al., 2005; Pereira et al., 2006; Tapio et al., 2006). The absence of haplogroups $\mathrm{D}$ and $\mathrm{E}$ is a logical result since these haplogroups are the rarest and were found only in the Caucasus and in Turkey.

If we compare the obtained distribution of mtDNA haplogroups in the investigated sheep breeds with available data, then it can be concluded that it has a large contribution, characteristic of Asian breeds of haplogroup A with predominance of haplogroup B, common in European breeds of modern sheep and in the countries of the Eastern The Mediterranean.

\section{Conclusion}

Thus, most of the investigated sheep belong, as expected, to haplogroup $\mathrm{A}$, which dominates in Asian countries with semi-desert regions, as well as haplogroup C, located in third place. Unexpected is the significant contribution of haplogroup B since this haplogroup is common in European breeds of modern sheep, as well as in the countries of the Eastern Mediterranean. Phylogenetic analysis indicated that differences among the studied breeds were less pronounced than expected, what the extensive transportation and trade of sheep may explain in the past.

\section{Acknowledgement}

The authors are thankful to Khamzin K.P. (Kazakh Scientific Research Institute of Sheep Breeding), Traisov 
B.B., Smagulov D.B. (Zhangir khan West Kazakhstan agrarian and technical university) and the staff from farm "Batai-Shu" in Jambyl region for help in sample collection. This study was supported by Ministry of Education and Science of the Republic of Kazakhstan (grant no. 0115PK01774).

\section{Author's Contributions}

All authors equally contributed in this work.

\section{Ethics}

This article is original and contains unpublished material. The corresponding author confirms that all of the other authors have read and approved the manuscript and there are no ethical issues involved.

\section{References}

Abilov, B.T., V.A. Shakhanov and I.N. Sharko, 2012. Meat qualities of fine-fleeced young sheep using secondary raw materials of starch production in feeding. Sheep Goats Woolen Field, 2: 74-76.

Balmont, V.A., 1965. Blue wool sheep breeding. AlmaAta, 144.

Berus, V.K., S.R. Ospanov and D.M. Sadyrov, 2013. Kazakhstan Merinos (The Merke zonal type). 1st Edn., Almaty, pp: 374.

Bradley, D.G., D.E. MacHugh, P. Cunningham and R.T. Loftus, 1996. Mitochondrial diversity and the origins of African and European cattle. Proc. Nat. Acad. Sci. USA, 93: 5131-5135. PMID: 8643540

Chen, S.Y., Z.Y. Duan, T. Sha, J. Xiangyu and S.F. $\mathrm{Wu}$ et al., 2006. Origin, genetic diversity and population structure of Chinese domestic sheep. Gene, 376: 216-223.

DOI: $10.1016 /$ j.gene.2006.03.009

Fernandez, H., S. Hughes, J.D. Vigne, D. Helmer and G. Hodgins et al., 2006. Divergent mtDNA lineages of goats in an Early Neolithic site, far from the initial domestication areas. PNAS, 103: 15375-15379. DOI: $10.1073 /$ pnas.0602753103

Gorkhali, N.A., J.L. Han and Y.H. Ma, 2015. Mitochondrial DNA Variation in Indigenous sheep (Ovis aries) Breeds of Nepal. Tropical Agric. Res., 26: 632-641. DOI: 10.4038/tar.v26i4.8125

Hall, T.A., 1999. BioEdit: A user-friendly biological sequence alignment editor and analysis program for Windows 95/98/NT. Nucleic Acids Symposium Series, 41: 95-98.

Hiendleder, S., B. Kaupe, R. Wassmuth and A. Janke, 2002. Molecular analysis of wild and domestic sheep questions current nomenclature and provides evidence for domestication from two different subspecies. Proc. Royal Society London, 269: 893-904.

DOI: $10.1098 / \mathrm{rspb} .2002 .1975$
Koseniuk, A. and E. Slota, 2016. Mitochondrial control region diversity in Polish sheep breeds. Arch. Anim. Breed., 59: 227-233. DOI: 10.5194/aab-59-227-2016

Larson, G., K. Dobney, U. Albarella, M. Fang and E. Matisoo-Smith et al., 2005. Worldwide phylogeography of wild boar reveals multiple centers of pig domestication. Science, 307: 1618-1621. DOI: $10.1126 /$ science. 1106927

Liu, J., X. Ding, Y. Zeng, Y. Yue and X. Guo et al., 2016. Genetic diversity and phylogenetic evolution of Tibetan sheep based on mtDNA D-loop sequences. PLoS ONE, 11: e0159308-e0159308.

DOI: 10.1371/journal.pone.0159308

Loftus, R.T., D.E. MacHugh, D.G. Bradley, P.M. Sharp and P. Cunningham, 1994. Evidence for two independent domestications of cattle. Proc. Nat. Acad. Sci. USA, 91: 2757-2761. PMID: 8146187

Luikart, G., L. Gielly, L. Excoffier, J.D. Vigne and J. Bouvet et al., 2001. Multiple maternal origins and weak phylogeographic structure in domestic goats. Proc. Nat. Acad. Sci. USA, 98: 5927-5932. DOI: $10.1073 /$ pnas.091591198

Lushnikov, V.P., T.M. Giro and S.I. Khvylya, 2013. Quality of lamb from adult ewes. Sheep Goats Woolen Field, 4: 10-13.

Meadows, J.R., I. Cemal, O. Karaca, E. Gootwine and J.W. Kijas, 2007. Five ovine mitochondrial lineages identified from sheep breeds of the near East. Genetics, 175: 1371-1379. DOI: $10.1534 /$ genetics. 106.068353

Meadows, J.R., K. Li, J. Kantanen, M. Tapio and W. Sipos et al., 2005. Mitochondrial sequence reveals high levels of gene flow between breeds of domestic sheep from Asia and Europe. Hered, 96: 494-501. DOI: $10.1093 /$ jhered/esi100

Ombayev, A.M., B.I. Musabayeva and K.P. Khamzin, 2013. Current state and development prospects of sheep breeding in Kazakhstan. Sheep Goats Woolen Field, 2: 85-85.

Othman, O.E., L. Pariset, E.A. Balabel and M. Marioti, 2015. Genetic characterization of Egyptian and Italian sheep breeds using mitochondrial DNA. J. Genetic Eng. Biotechnol., 13: 79-86. DOI: 10.1016/j.jgeb.2014.12.005

Pedrosa, S., M. Uzun, J.J. Arranz, B. Gutiérrez-Gil and F. San Primitivo et al., 2005. Evidence of three maternal lineages in near eastern sheep supporting multiple domestication events. Proc. Royal Society London, 272: 2211-2217. DOI: 10.1098/rspb.2005.3204

Pereira, F., S.J. Davis, L. Pereira, B. McEvoy and D.G. Bradley et al., 2006. Genetic signatures of a Mediterranean influence in Iberian Peninsula sheep husbandry. Molecular Biol. Evolut., 23: 1420-1426. DOI: $10.1093 / \mathrm{molbev} / \mathrm{ms} 1007$ 
Rafia, P. and A. Tarang, 2016. Sequence variations of mitochondrial DNA displacement-loop in Iranian indigenous sheep breeds. Iran. J. Applied Anim. Sci., 6: 363-368

Rasali, D.P., J.N.B. Shrestha and G.H. Crow, 2006. Development of composite sheep breeds in the world: A review. Canad. J. Anim. Sci., 86: 1-24. DOI: $10.4141 /$ A05-073

Sasazaki, S., S. Odahara, C. Hiura, F. Mukai and H. Mannen, 2006. Mitchondrial DNA variation and genetic relationships in Japanese and Korean cattle. Asian-Australasian J. Anim. Sci., 19: 1394-1398. DOI: 10.5713/ajas.2006.1394

Shauyenov, S., Y. Islamov, S. Narbayev and D. Ibrayev, 2016. Effect of sire breed on the productivity of Kazakh mutton-semifine-wool sheep. Indian J. Anim. Res., 50: 418-424. DOI: 10.18805/ijar.9493

Tanaka, K., C.D. Solis, J.S. Masangkay, K. Maeda and Y. Kawamoto et al., 1996. Phylogenetic relationship among all living species of the genus Bubalus based on DNA sequences of the cytochrome $b$ gene. Biochem. Genet., 34: 443-452. PMID: 9126673

Tapio, M., N. Marzanov, M. Ozerov, M. Cinkulov and G. Gonzarenko et al., 2006. Sheep mitochondrial DNA variation in European, Caucasian and central Asian areas. Molecular Biol. Evolut., 23: 1776-1783.

DOI: $10.1093 / \mathrm{molbev} / \mathrm{msl} 043$
Torekhanov, A.A., T.K. Kasenov and K.B. Omashev, 2011. In Kazakhstan a new breed of sheep "Etty Merinos" was created. Sheep Goats Woolen Field, 4: 12-13.

Traisov, B.B., Y.A. Yuldashbayev, K.G. Esengaliyev, A.K. Sultanova and A.K. Bozymova, 2015. Growth and development of lambs of the akzhaik sheep depending on selection. Biol. Med., 7: BM-074-15.

Upholt, W.B. and I.B. Dawid, 1977. Mapping of mitochondrial DNA of individual sheep and goats: Rapid evolution in the D loop region. Cell, 11: 571-583. DOI: 10.1016/0092-8674(77)90075-7

Watanabe, T., J.S. Masangkay, S. Wakana, N. Saitou and T. Tomita, 1989. Mitochondrial DNA polymorphism in native Philippine cattle based on restriction endonuclease cleavage patterns. Biochem. Genet., 27: 431-438. DOI: 10.1007/BF02399672

Wolf, C., J. Rentsch and P. Hubner, 1999. PCR-RFLP analysis of mitochondrial DNA: A reliable method for species identification. J. Agric. Food Chem., 7: 1350-1355. PMID: 10563979 